\title{
AS CONTRIBUICOÕES SOCIAIS E AMBIENTAIS DOS RECICLADORES E DOS FERROS VELHOS PARA OS CANAIS REVERSOS DE RESÍDUOS SÓLIDOS
}

\author{
Vitor Henrique de Melo Macedo ${ }^{1}$ \\ Gustavo Hermínio Salati Marcondes de Moraes ${ }^{2}$ \\ Nágela Bianca do Prado ${ }^{3}$
}

\begin{abstract}
RESUMO
O avanço tecnológico impacta no aumento do consumo de bens e, consequentemente, no aumento de resíduos inutilizáveis. Com isso surgem problemas quanto ao descarte incorreto de materiais que podem degradar o meio ambiente. Neste sentido, o objetivo desta pesquisa baseou-se em identificar as contribuições sociais e ambientais dos recicladores e dos ferros velhos para os canais reversos de resíduos sólidos. A partir de entrevistas com sucateiros, gestores de ecopontos, ferros velhos e pesquisa documental nas cidades Limeira e Itapetininga, ambas localizadas no Estado de São Paulo, foi observado a diversidade sociodemográfica dos indivíduos atuantes no ramo da reciclagem, os quais realizam a coleta de quantidades consideráveis de resíduos sólidos do ambiente urbano, cuja renda advinda da atividade é utilizada para fins de sobrevivência. Assim, pode-se concluir que os catadores compreendem os benefícios ambientais e sociais de suas atividades. Os atravessadores, por sua vez, promovem mudanças econômicas pessoais aos agentes coletores de forma a propiciar um ambiente mais favorável de negociação dos resíduos. Com as descobertas deste estudo, espera-se aumentar a consciência da importância desses agentes no meio social - inclusive para o desenvolvimento sustentável - por parte de órgãos públicos e privados a fim de garantir melhores estruturas de trabalho destes catadores.
\end{abstract}

Palavras-chave: Resíduos Sólidos. Reciclagem. Canais reversos. Impactos Socioambientais.

\footnotetext{
1 Graduando em Administração pela Universidade Estadual de Campinas (Unicamp) e empreendedor. E-mail: macedovitorh@gmail.com

2 Doutor e Mestre em Administração pela FGV-EAESP. Professor dos cursos de Administração e Administração Pública da Unicamp. E-mail: salati@unicamp.br

${ }^{3}$ Mestranda em Administração pela Unicamp. Especialista em Gestão Estratégica de Pessoas pela Unicamp. Tecnóloga em Gestão Empresarial pela Faculdade de Tecnologia de Americana (FATEC). E-mail: nagelabianca.prado@gmail.com
}

R. gest. sust. ambient., Florianópolis, v. 10, n. 2, p. 125-149, jun. 2021. 


\title{
THE SOCIAL AND ENVIRONMENTAL CONTRIBUTIONS OF RECYCLERS AND JUNKYARDS TO THE SOLID WASTE REVERSE CHANNELS
}

\begin{abstract}
Technological advances impact on the goods consumption increase and, consequently, in the unusable waste increase. As a result, problems arise regarding the incorrect disposal of materials that can degrade the environment. In this sense, the objective of this research was based on identifying the social and environmental contributions of recyclers and junkyards to the solid waste reverse channels. From interviews with scrap dealers, ecopoints managers, junkyards and documentary research in Limeira and Itapetininga cities, both located in São Paulo State, the socio-demographic diversity of individuals working in the recycling sector was observed, who perform the collection of quantities considerable amounts of solid waste from the urban environment, whose income from the activity is used for survival purposes. According to the research, it can be concluded that the collectors understand the environmental and social benefits of their activities. The intermediaries, in turn, promote personal economic changes to the collecting agents in order to provide a more favorable waste negotiation environment. With the findings of this study, it is expected to raise awareness of these agents' importance in the social environment - including for sustainable development - by public and private agencies in order to guarantee better working structures for these workers.
\end{abstract}

Keywords: Solid Waste. Recycling. Reverse Channels. Social and Environmental Impacts.

\section{INTRODUÇÃO}

$\mathrm{Na}$ modernidade, uma das grandes preocupações que afligem a humanidade é em relação à sustentabilidade das produções humanas. $\mathrm{O}$ consumo de bens vem aumentando e com eles, o uso de embalagens, devido ao surgimento constante de novas tecnologias e do período de obsolescência programada dos produtos (Cornieri \& Fracalanza, 2010, Perlin, Alvares, Kneipp, Vestena, \& Rossato, 2020). Estima-se que, em média, $99 \%$ dos bens comprados sejam descartados em seis meses (ONU, 2018), o que gera a preocupação pela quantidade de resíduos sólidos criados e descartados diariamente.

Como evidenciado, a estimativa é que o crescimento do descarte até 2030 seja $70 \%$ maior que na atualidade, chegando ao valor de 2,2 bilhões de toneladas anuais até 2025 (ONU, 2019). Tais dados levam a analisar o impacto causado pelas produções, consumo e descarte destes produtos, como problemas relacionados aos danos ao planeta, como poluição e contaminação do ar, água e solo, risco de danos à saúde, além da questão da sustentabilidade das matérias primas, que contempla a

R. gest. sust. ambient., Florianópolis, v. 10, n. 2, p. 125-149, jun. 2021. 
definição de sustentável: produzir suprindo a demanda atual, sem prejudicar o futuro da civilização e do planeta (Giannetti, Bonilla, \& Almeida, 2013, D’Adamo, Ferella, Gastaldi, Maggiore, Rosa, \& Terzi, 2019, Perlin et al., 2020).

São resíduos sólidos todos os materiais, substâncias, objetos ou bens descartados resultantes das atividades humanas em sociedade, por definição da Política Nacional de Resíduos Sólidos (PNRS). Ademais, são considerados resíduos, pois não apresentam mais utilidade para o consumidor primário, entretanto há caminhos que esses resíduos podem tomar para reintegrar a cadeia de consumo em sua essência, de forma parcial ou como novos produtos.

Para Klein, Gonçalves-Dias e Jayo (2018), os resíduos sólidos urbanos constituem um grande desafio na agenda das políticas públicas no Brasil, pois a disposição incorreta desses materiais causa danos ao solo, aos mananciais, a proliferação de insetos, a intensificação de enchentes e o aumento de doenças como a dengue. Ademais, o autor menciona que os impactos ultrapassam a esfera ambiental, afetando socialmente as condições insalubres dos catadores urbanos.

Nesse contexto, os canais reversos de bens de consumo estão presentes nas diversas etapas de comercialização e industrialização onde há descartes de matéria-prima, até a sua reintegração ao processo produtivo (Leite, 2009, Souza, Paula, \& Souza-Pinto, 2012). Existem três subsistemas reversos: reuso, remanufatura e reciclagem (Leite, 2009). No primeiro deles, denominado "reuso", os produtos são limpos e deixados em condições de reutilização pelo consumidor, mas não há reparo ou incremento no produto descartado. No segundo, chamada de "remanufatura", o produto é reconstituído com a mesma finalidade original, com a substituição de componentes. Já o terceiro, nominada "reciclagem", diz respeito ao canal reverso em que o produto não continua com sua funcionalidade original. Estes materiais podem ser reutilizados no processo de produção dos produtos originais ou ainda servir de matéria-prima para outras indústrias (Leite, 2009, Souza et al., 2012).

Nos países em desenvolvimento como o Brasil, essa coleta de material descartado pode ser uma estratégia de sobrevivência, como uma alternativa de trabalho frente ao desemprego, por exemplo; ou ainda um ramo comercial lucrativo, no caso das vendas em grande escala e triagem dos diferentes tipos de materiais. Os trabalhadores que atuam com a coleta de reciclagem, de forma individual ou coletiva, em português, podem ser chamados de "catadores", "coletores",

R. gest. sust. ambient., Florianópolis, v. 10, n. 2, p. 125-149, jun. 2021. 
"carroceiros", "sucateiros" ou "recicladores" (Souza et al., 2012). Já aqueles que atuam buscando a compra de matérias em escala podem ser denominados como "intermediários" ou "atravessadores" (Aguiar, 1999, Cruz \& Quandt, 2007, Gonçalves-Dias \& Teodósio, 2006).

Há, portanto, um comércio incentivado pelas indústrias de commodities de recicláveis, que agem como destino final do resíduo sólido reciclável em posse de atravessadores (Medina, 1997) e de sucateiros organizados em coletivos, pois conseguem aumentar a escala de material coletado, podendo se tornar um fornecedor da indústria aumentando seus ganhos reais (Medina, 2000, Paiva, 2004, WIEGO, 2008). Contudo, o incentivo da indústria abre espaço para que atravessadores e sucateiros atuem com outros dois subsistemas reversos: através do comércio local com pessoas físicas ou jurídicas, auxiliando na longevidade de peças e produtos (Leite, 2009).

A temática dos catadores tem sido alvo de investigação de estudiosos do tema, mas ainda há um gap em relação aos agentes dessa cadeia produtiva, bem como do envolvimento desses profissionais com intermediários ou atravessadores (Carmo, Oliveira, \& Arruda, 2006, Cruz \& Quandt, 2007, Gonçalves-Dias \& Teodósio, 2006, Paiva, 2004, Medina, 1997, Rodriguez, 2004, WIEGO, 2008). Neste sentido, o problema de pesquisa e o objetivo serão apresentados a seguir.

Dada a contextualização apresentada, o presente artigo tem o seguinte questionamento: "Quais são as contribuições sociais e ambientais dos recicladores e dos ferros velhos para os canais reversos de resíduos sólidos?". Sendo assim, de maneira geral, esta pesquisa objetiva identificar as contribuições sociais e ambientais dos recicladores e dos ferros velhos para os canais reversos de resíduos sólidos, abordando os três subsistemas reversos: reuso, remanufatura e reciclagem sob a ótica dos catadores e atravessadores.

O presente artigo está organizado de forma a contemplar, após esta introdução, a fundamentação teórica na seção dois; a metodologia na seção três; a discussão dos resultados na quatro; a conclusão na seção cinco; e, por último, as referências utilizadas.

R. gest. sust. ambient., Florianópolis, v. 10, n. 2, p. 125-149, jun. 2021. 


\section{REFERENCIAL TEÓRICO}

\subsection{CONTEXTO DO SURGIMENTO DO SETOR DA RECICLAGEM}

Após as revoluções industriais e a intensificação da produção em massa, na qual a economia global se sustenta, diminuiu-se a produção de produtos duráveis e optou-se por materiais de baixa resistência como forma de diminuição do custo de produção para empresas, e de compra para os clientes. Estes produtos passaram, também, a apresentarem uma durabilidade, o que não seria um impedimento, uma vez que as constantes atualizações tecnológicas levariam as pessoas a adquirirem novos bens atualizados (Pacheco, 2012). Contudo, houve então um aumento dos resíduos sólidos, principalmente de materiais como papelão, plástico e vidro gerando uma oportunidade e uma necessidade para o desenvolvimento do setor da reciclagem (Cornieri \& Fracalanza, 2010, Figueiredo, 2011, Leite, 2000).

A falta de estímulos e de compreensão das atividades de reciclagem acarretam na desinformação sobre os materiais e a continuada destinação incorreta desses resíduos, que culminam em impactos ambientais e econômicos (ANCAT, 2014). Dentre os principais efeitos ambientais, a reciclagem permite a minimização da exploração de recursos naturais, uma vez que diversos são os materiais totalmente aproveitáveis no processo de reciclagem, como metal e cobre; ou parcialmente aproveitáveis, como aparas de papéis.

Como efeitos benéficos ao meio ambiente pode-se citar a redução da poluição do solo, da água e do ar, uma vez que as atividades de extrair novas matérias-primas de produção e evitar a destinação incorreta do material, ademais do processo de reciclagem do material, demandam menor uso recursos (ANCAT, 2014). Já pela ótica econômica, a reciclagem impacta no orçamento público, pois diminui a necessidade de aterros sanitários, bem como no ambiente privado, ao reduzir o custo de produção das indústrias. Ademais, a reciclagem é a fonte principal ou exclusiva de renda de milhares de famílias que atuam diretamente com a atividade, sejam atravessadores ou catadores (Asim, Batool, \& Chaudhry, 2012).

R. gest. sust. ambient., Florianópolis, v. 10, n. 2, p. 125-149, jun. 2021. 


\subsection{DAS LACUNAS DA LOGÍSTICA REVERSA AO TRABALHO INFORMAL}

A compreensão da cadeia de logística de reciclagem e seus participantes é crucial para ter um entendimento completo a respeito das situações, comportamentos e tendências do mercado (Aguiar, 1999, Pacheco, 2012).

O termo "logística reversa", o qual passou a ser utilizado após 1990 com a preocupação das empresas sobre o descarte de seus produtos após a utilização, tem foco no inverso da "logística direta", que é responsável por levar os produtos do centro de distribuição para o mercado consumidor, isto é, levar o produto após o consumo de volta à produção, onde poderá retornar ao ciclo do produto (Leite, 2009).

Neste discurso, Pegorin e Araújo (2018) trazem uma contribuição quanto ao saneamento urbano, o qual inclui a coleta e a destinação correta de materiais inutilizáveis como uma forma de promover a sustentabilidade local. Este termo inclusive se desdobra, segundo as autoras, no conceito de "cidades inteligentes", pois tal procedimento envolve a logística reversa como forma de promoção de qualidade de vida urbana e equilíbrio ambiental.

Entretanto, os problemas de implementação do sistema de logística reversa para as indústrias são diversos, tais como custo do retorno; localização fragmentada do descarte; contaminação por outros produtos, dentre outros fatores que fazem com que cada indústria ainda não consiga ser responsável por recuperar os produtos de sua autoria. É neste ponto que existem e atuam os agentes recicladores, que retiram parte dos resíduos sólidos passíveis de reciclagem de descartes comuns para beneficiamento e destinação às indústrias (Leite, 2009, Giannetti et al., 2013).

A maior parte da destinação de resíduos sólidos segue para aterros sanitários, 59,1\% (ABRELPE, 2017) e, apesar da cobertura de coleta de resíduos sólidos urbanos ter uma abrangência de 91,24\% no território brasileiro (ABRELPE, 2017), ainda existem cidades brasileiras sem qualquer iniciativa de coleta seletiva. Os catadores autônomos e informais, sejam com seus carrinhos próprios ou alugados, são responsáveis pela maior parte da coleta dos materiais que vão para os aterros (Chagas \& Neto, 2012, Medeiros \& Macêdo, 2006). As porcentagens de

R. gest. sust. ambient., Florianópolis, v. 10, n. 2, p. 125-149, jun. 2021. 
materiais nos aterros variam conforme aponta o Anuário da Reciclagem da Associação Nacional dos Catadores e Catadoras de Materiais Recicláveis (ANCAT) de 2018. Porém, os materiais com maior taxa de reciclagem são aqueles que possuem maior demanda das indústrias (Medina, 1997, Leite, 2009), como é o caso de papel e latas de alumínio que possuem melhores preços em relação aos demais resíduos sólidos.

Os participantes da cadeia de logística da reciclagem podem ser separados com base em suas interações com a cadeia de logística reversa sendo estas: devolução, recebimento, coleta e processamento. A primeira (devolução) pode ser realizada por qualquer agente, como consumidores no descarte, ou indústrias - no caso de sobras de produção - que chegam até os receptores (agentes como os fornecedores, fabricantes, atacadistas ou varejistas) que irão comercializar com os intermediários independentes a coleta desse material, sendo empresas de coletores privados ou cooperativas. Ao destino final são responsáveis pela transformação, que realizarão o processo de processamento da reciclagem (Gonçalves-Dias \& Teodósio, 2006).

Nesta pesquisa, o foco é nos catadores e atravessadores, os quais atuam tanto como receptores quanto coletores.

\subsection{OS CATADORES, OS ATRAVESSADORES E OS “ECOPONTOS”}

Os catadores são pessoas em situação de vulnerabilidade que encontraram na reciclagem um meio sobrevivência (Medeiros \& Macêdo, 2006). Para Asim et al. (2012), os catadores possuem características sociodemográficas distintas, ou seja, são homens e mulheres de diferentes idades podendo ser refugiados ou socialmente desfavorecidos, os quais dependem do estado de conservação do item para obterem algum lucro. Mesmo marginalizados pela sociedade e sendo o elo mais fraco da cadeia, eles agem como principais responsáveis pela reciclagem, atuando em aterros sanitários ou nos centros urbanos, recolhendo resíduos sólidos passíveis de comercialização, normalmente com um carrinho para guardar o material e chegando a andar dezenas de quilômetros por dia, com baixas margens de ganho,

R. gest. sust. ambient., Florianópolis, v. 10, n. 2, p. 125-149, jun. 2021. 
com exposições a riscos nos aterros sanitários e nas situações de trabalho, e por vezes são excluídos da sociedade e se encontram em situações de preconceito.

Ademais, eles podem ser autônomos ou agregados a uma cooperativa, onde ganham mais força de atuação, ao juntarem maiores quantidades de materiais e negociarem melhores preços com atravessadores ou até mesmo com indústrias (Medina, 2000, Paiva, 2004, WIEGO, 2008). Neste sentido, é inclusive possível que estes trabalhadores façam investimentos em maquinários necessários para melhorar o beneficiamento dos resíduos sólidos (Cruz \& Quandt, 2007; Figueiredo, 2001).

Uma alternativa para o trabalho de catadores, são os "ecopontos", que surgem como uma Política Pública para lidar com os resíduos sólidos gerados na sociedade, surgindo em diversas cidades do Brasil.

Tais pontos agem como uma forma de evitar a destinação ou despejo incorreto dos resíduos, que por vezes pode ocasionar contaminações variadas ou acúmulo indesejado em locais urbanos (Alvarez, 2014). Os ecopontos, ademais, são instalações mantidas pela prefeitura municipal local que cede o espaço aos catadores que atuam como gestores responsáveis pelo espaço, realizando o atendimento aos frequentadores e a orientação de destino correta dos resíduos.

Dentre os resíduos aceitáveis em ecopontos estão resíduos de construção civil, móveis velhos, objetos de madeira e materiais recicláveis. Entretanto, os ecopontos não podem coletar resíduo domiciliar comum, lixo eletrônico, óleo e material contaminado, como o hospitalar. Os resíduos sólidos aceitos podem ser destinados a aterros (entulhos), assim como podem ser direcionados à cadeia logística da reciclagem. O eco coletor responsável tem autonomia sobre a comercialização do material reciclável com atravessadores ou indústrias, onde a receita gerada é convertida em lucro para os responsáveis do local e demais trabalhadores (Alvarez, 2014). A renda de catadores filiados a ecopontos depende da quantidade de material reciclável que coletam ou recebem, bem como é de sua responsabilidade as negociações com atravessadores. Vale ressaltar que estes agentes não recebem salários da prefeitura pela atuação, mas apenas o espaço de trabalho.

Os atravessadores ou intermediários são gestores de ferro velhos privados, podendo ser categorizados em pequenos, médios ou grandes sucateiros (Chagas \& Neto, 2012). A vantagem comercial de médios e grandes ferros velhos é que, por

R. gest. sust. ambient., Florianópolis, v. 10, n. 2, p. 125-149, jun. 2021. 
possuírem maior investimento em equipamentos, espaço e pessoal, obtém vantagens para comercializar grandes quantidades com o destino final: as indústrias de reciclagem, dentre elas: fábricas, usinas, siderúrgicas etc. Tais indústrias costumam se localizar em grandes centros e aceitam apenas a entrega de grandes quantidades de materiais trabalhando, portanto, com médios ou grandes sucateiros, ou ainda com cooperativas (Cruz \& Quandt, 2007, Leite, 2009).

Os pequenos e médios atravessadores, por sua vez, comumente atuam comercializando diversos tipos de materiais recicláveis adquirindo-os de coletores, cooperativas ou outros comércios, enquanto grandes sucateiros focam em materiais específicos segmentados por mercados, como por exemplo comercializando apenas aparas de papel, plásticos, vidros ou metais (Chagas \& Neto, 2012, Leite, 2000), se diferenciando pela comercialização de milhares de toneladas mensais; por possuírem grandes áreas para estocagem e processamento, utilizando de equipamento, como prensas hidráulicas, máquinas especializadas, trituradores, dentre outros que garantem vantagens na comercialização final com a indústria recicladora ao fornecerem o material na etapa anterior ao reprocessamento.

De acordo com Leite (2009), no espaço de trabalho de catadores e atravessadores surge uma oportunidade de negócio e atuação paralela que não interfere no desempenho com a reciclagem destinada à indústria, podendo, no entanto, fornecer ganhos unitários maiores do que os adquiridos com as indústrias. A comercialização de matérias para reuso e remanufatura para os interessados, seja de forma passiva ou ativa, oferece ganhos maiores, pois a venda do produto, seja de forma total ou parcial, se dá de acordo com o peso do mesmo. Assim, há uma extensão da vida útil do produto, gerando benefícios a quem comercializa e quem procura o material.

\subsection{OS REFLEXOS SOCIAIS E AMBIENTAIS DA RECICLAGEM}

Os efeitos da reciclagem refletem nas esferas socioeconômicas e ambientais sendo a primeira o principal motivador (Leite, 2000, Figueiredo, 2011), pela necessidade de renda da base dos agentes, enquanto as vantagens ambientais são

R. gest. sust. ambient., Florianópolis, v. 10, n. 2, p. 125-149, jun. 2021. 
exploradas pelas indústrias como forma de participarem de programas, marketing, metas ou na redução de custos.

As vantagens ambientais mais reconhecidas pelos catadores e sucateiros são referentes a redução da poluição do solo, água e ar. Mas há, ainda, a minimização da exploração de recursos naturais, uma vez que as indústrias utilizam parte dos resíduos recicláveis para seus processos - estratégia que está diretamente atrelado a redução do custo de produção. A diminuição de resíduos sólidos descartados incorretamente gera a redução de gases no processo de decomposição dos materiais. Este impacto ambiental também é refletido na melhoria da saúde das populações periféricas que se encontram próximas das áreas de aterros sanitários (Siqueira \& Moraes, 2009; CEMPRE, 2014; ABRELPE, 2017).

$\mathrm{Na}$ esfera econômica, toda a cadeia se beneficia financeiramente, gerando renda para milhares de pessoas, desde catadores até grandes empresas privadas de atravessadores, cuja cada parte da cadeia fica com uma parcela do valor final pago pela indústria (ANCAT, 2018).

Entre as contribuições sociais, as cooperativas que se iniciam como estratégia de sobrevivência em busca de melhores condições de trabalho e renda, realizam uma grande troca de conhecimento entre os catadores e entre outras cooperativas, onde são estimulados o desenvolvimento sustentável, ambiental, cultural, político, social, econômico e local. Cooperativas próximas com atuações diferentes por vezes podem auxiliar-se. Portanto, há uma vantagem local do trabalho para desenvolvimento pessoal nesses âmbitos, que contribuem para retirar os indivíduos de situações de risco, incluindo o uso de substâncias ilícitas ou envolvimento com crimes (Cruz \& Quandt, 2007).

\section{METODOLOGIA}

Dada a problemática proposta esta pesquisa é de abordagem qualitativa, uma vez serão exploradas percepções dos participantes (Benbasat, Goldstein, \& Mead, 1987), tendo como perspectiva os catadores de lixo e os gestores de ferro velho. A pesquisa pode ser caracterizada, em relação aos objetivos, como exploratória, a qual utilizará da estratégia dos estudos de casos múltiplos (GIL,

R. gest. sust. ambient., Florianópolis, v. 10, n. 2, p. 125-149, jun. 2021. 
2006). O projeto foi submetido ao Comitê de Ética e Pesquisa por meio da Plataforma Brasil, e foi aprovado antes de ser iniciado.

Os estudos de casos foram realizados com catadores de lixo, ou sucateiros, e com gestores de ferro velho das cidades de Limeira e Itapetininga, ambas localizadas no Estado de São Paulo. A amostra é de característica não probabilística e por conveniência. As fontes de evidências utilizadas foram entrevistas, observação direta e pesquisa documental. Assim, buscou-se entrevistar, via questionário semiestruturado, cinco gestores de ecopontos na cidade de Limeira onde há cerca de 150 pessoas cadastradas no projeto Reciclar Solidário. Mais especificamente, foram entrevistados atravessadores de portes e regiões diferentes, com atuação de materiais recicláveis diversos, sendo um atravessador de porte médio e localizado Limeira, e quatro de Itapetininga - destes, dois são de médio e dois são de pequeno porte.

Com as distintas fontes de informação, foi possível realizar a triangulação de dados, a qual permitiu uma descrição mais rica e detalhada dos fenômenos, explorando as diferenças temporais e locais como forma de investigação comparativa das diferentes fontes de validação (Denzin, 1978).

\section{DISCUSSÃO DOS RESULTADOS}

\subsection{ENTREVISTA COM CATADORES INDIVIDUAIS}

$\mathrm{Na}$ amostra referente aos catadores individuais, três pessoas da cidade de Itapetininga, que atuam com materiais de metais, papéis e plásticos, utilizando carrinhos para auxiliar no transporte, foram entrevistadas. Os indivíduos não realizam a compra do material, mas fazem a coleta em residências, pequenos comércios ou descartados de forma indevida no meio ambiente em torno de suas localidades. Ademais, eles utilizam de terrenos abandonados ou próprios para armazenar os resíduos.

Segundo os mesmos, o rendimento financeiro se dá de acordo com acúmulo do material que os mesmos coletam. Após a coleta, inclusive, o material fica armazenado nesses terrenos e, posteriormente, são retirados por atravessadores ou

R. gest. sust. ambient., Florianópolis, v. 10, n. 2, p. 125-149, jun. 2021. 
entregue em depósitos. O repasse dos resíduos varia conforme a quantidade coletada, a possibilidade de utilidade dos resíduos, da proximidade com os atravessadores, e da precificação. Assim, os ganhos variam conforme a quantidade de materiais coletados e do preço pago por atravessadores.

Os entrevistados também buscam realizar a triagem e limpeza de impurezas dos materiais, como forma de valorizar o trabalho e auxiliar nas negociações de preços, bem como firmar acordos informais de fidelidade de comercialização com os atravessadores. Portanto, o lucro financeiro é a principal motivação do trabalho realizado, assim como o impacto social reconhecido pelos mesmos. Ademais, os entrevistados observam na reciclagem uma oportunidade de trabalho para manutenção da sobrevivência. Entretanto, observou-se que quando esses indivíduos atuam de forma individual, seja por motivações próprias ou impossibilidade de atuar em coletivo, não são beneficiados pelas contribuições sociais citadas por Cruz e Quandt (2007).

Por fim, são percepções dos trabalhadores que a destinação dos resíduos sólidos para a cadeia logística da reciclagem gera vantagens tanto ao meio ambiente, assim como impede o descarte incorreto do material aos aterros sanitários ou na natureza.

\subsection{ENTREVISTA COM GESTORES DE ECOPONTOS}

Como relatado no referencial teórico, os ecopontos surgem como uma possibilidade para o trabalho dos catadores. Da amostra composta por 150 pessoas cadastradas no projeto Reciclar Solidário, 25 pessoas desenvolvem atividades em 11 ecopontos espalhados estrategicamente pela cidade (Alvarez, 2014), com horário de funcionamento das 7:30 às 18 horas (de segunda a sábado), e aos domingos das 7:30 às 12 horas. A quantidade de catadores fixos em cada ecoponto varia. Porém, mantém-se uma média de dois responsáveis. Entretanto, existem pontos de convergência de outros catadores que contribuem permanentemente ou por um período limitado.

A seguir, a Tabela 1 será apresentada referenciando o desempenho somado dos Ecopontos de Limeira no ano de 2019 a respeito da comercialização de R. gest. sust. ambient., Florianópolis, v. 10, n. 2, p. 125-149, jun. 2021. 
materiais recicláveis coletados pelos catadores. Percebe-se, na Tabela 1, uma quantidade significativa de material retirado das ruas de Limeira pelos catadores, fato que implica na redução de resíduos dispostos no ambiente urbano que podem poluir o meio ambiente.

Tabela 1 - Relatório Reciclar Solidário (Grupo Ecopontos)

\begin{tabular}{ccc}
\hline Material & Quantidade em quilograma & Percentual \\
\hline Papéis & $373.268,20$ & $53 \%$ \\
\hline Plásticos & $148.082,12$ & $21 \%$ \\
\hline Vidros & $60.271,80$ & $8 \%$ \\
\hline Metais & $132.446,73$ & $18 \%$ \\
\hline Total & $\mathbf{7 1 4 . 0 6 8 , 8 8}$ & $\mathbf{1 0 0 \%}$ \\
\hline \multicolumn{2}{c}{}
\end{tabular}

As informações a respeito dos responsáveis entrevistados nesta amostra, compondo as características e do desempenho mensal dos ecopontos são apresentadas na Tabela 2.

Tabela 2 - Caracterização dos entrevistados

\begin{tabular}{cccccc}
\hline $\begin{array}{c}\text { Gênero do(a) } \\
\text { responsável }\end{array}$ & $\begin{array}{c}\text { Idade do(a) } \\
\text { responsável }\end{array}$ & $\begin{array}{c}\text { Tempo de } \\
\text { trabalho } \\
\text { com } \\
\text { reciclagem }\end{array}$ & $\begin{array}{c}\text { Tempo de } \\
\text { trabalho no } \\
\text { ecoponto }\end{array}$ & $\begin{array}{c}\text { Quantidade } \\
\text { de } \\
\text { catadores }\end{array}$ & $\begin{array}{c}\text { Quantidade total } \\
\text { de resíduos } \\
\text { sólidos } \\
\text { recicláveis }\end{array}$ \\
\hline Feminino & 60 anos & - & - & 2 & - \\
\hline Masculino & 55 anos & 12 anos & 10 anos & 5 & 10 toneladas \\
\hline Feminino & 63 anos & 42 anos & 12 anos & 2 & - \\
\hline Masculino & 38 anos & 18 anos & 7 anos & 6 & 30 toneladas \\
\hline Feminino & 58 anos & 5 anos & 3 anos & 4 & 15 toneladas \\
\hline \multicolumn{5}{r}{ Fonte: Dados obtidos pelos autores (2019). } \\
\hline \multicolumn{5}{c}{}
\end{tabular}

Percebe-se, na Tabela 2, que as características dos gestores entrevistados variam conforme descrito por Asim et al. (2012). Ademais, os cinco ecopontos visitados na cidade de Limeira apresentam características e comportamentos semelhantes, seguindo o guia de operações fornecido pela prefeitura, mas ainda assim, cada ecoponto apresenta diferenciais físicos e operacionais que influenciam na maneira de trabalhar e na eficiência (Alvarez, 2014).

A começar pelo terreno que o ecoponto está instalado, com diferentes tamanhos e formatos, há um planejamento e organização interna para facilitar a

R. gest. sust. ambient., Florianópolis, v. 10, n. 2, p. 125-149, jun. 2021. 
entrada de material e a organização da separação conforme a classificação geral do resíduo sólido (entulho, metais, plásticos, papéis etc.). Nos cinco casos observados, há presença de um desnível de terreno que é utilizado como plataforma de apoio para carregar caçambas de entulho ou outros materiais, algo pensado na hora da escolha do local para o ecoponto (Alvarez, 2014).

A principal particularidade de cada ecoponto está na estratégia em obter materiais recicláveis de forma ativa, sendo essa realizada com carrinho ou com veículos, podendo ser picape ou caminhão, o que influencia diretamente no raio da área de coleta, bem como quantidade de material e frequência coletada. Ademais, a utilização de carrinho ou veículos, depende dos próprios gestores dos ecopontos, que tenham a possibilidade de adquirir o bem através de investimento próprio, torna a operação mais rentável, mas na maioria dos casos, a renda gerada com o ecoponto não é o suficiente para poupar para os investimentos em veículos, sendo a receita destinado a necessidades básicas dos envolvidos (Cruz \& Quandt, 2007, Leite, 2000, Medeiros \& Macêdo, 2006).

Conforme cada gestor são desenvolvidas e empregadas estratégias diferentes para a coleta. Para o ecoponto manter-se em funcionamento, por exemplo, é preciso manter um catador responsável. No caso de haver apenas um ou dois ecos coletores no ecoponto, se torna necessário que um deles atue apenas de forma passiva durante o expediente. Já no caso de haver mais catadores no local, o responsável pode optar por também coletar material durante o período de experiente.

Em alguns casos há a especialização na retirada de material. Fatores que influenciam positivamente no aumento de ganhos, conforme apontado por Medina (2000), Paiva (2004) e WIEGO (2008), pois a coletividade impacta em aumento nos ganhos dos catadores, seja através de ecopontos, cooperativas ou outras formas de trabalho.

$\mathrm{Na}$ estratégia de coleta ativa há pontos fixos de coletas semanais ou mensais, muitas vezes agendadas, podendo ser de empresas, comércios, fábricas, condomínios, dentre outros tipos de consumidores. Isso garante benefício mútuo para os consumidores que destinam seus resíduos sólidos passíveis de reciclagem sem custos, e aos catadores que se beneficiam do lucro sobre o material. Para os casos dos resíduos sólidos não recicláveis, os catadores não realizam o transporte

R. gest. sust. ambient., Florianópolis, v. 10, n. 2, p. 125-149, jun. 2021. 
por não comercializarem o material, ficando a destinação correta a cargo dos consumidores sob orientação dos catadores.

Em alguns casos, os materiais já vêm triados, em outras, os próprios catadores realizam a triagem do material dentre as subclassificações e, se necessário, realizam a limpeza de impurezas no material, tais como, borrachas e parafusos de ferro de alumínio. A triagem e limpeza do material é um fator crucial que impacta de forma considerável no preço final que irão comercializar o produto, bem como na aceitação do material para compradores mais exigentes.

Quanto às atividades de controle de estoque, finanças, organização local e quantidade vendida e recebida, são responsabilidades inerentes ao gestor. Entretanto, a prefeitura disponibiliza uma análise mensal dos resultados, com base nas notas fiscais emitidas entregues para a análise dos benefícios da política pública.

A comercialização dos ecopontos é feita com base em decisão própria, isto é, os gestores possuem autonomia de escolher com quem comercializar. Desta forma, a estratégia de contato com os compradores dos produtos varia, podendo-se optar pelo melhor custo benefício a curto ou longo prazo, pela geração de parcerias de compra fixa mensal com atravessadores exclusivos, e pela escolha daqueles com melhor oferta de preço no período (Alvarez, 2014, Cruz \& Quandt, 2007, Leite, 2009).

No ambiente da reciclagem também é comum a realização de cotações próprias, bem como o recebimento de ofertas de compradores de outras regiões. Uma diferença entre o panorama geral de catadores e atravessadores é que quando os preços de materiais recicláveis estão em alta no mercado, os catadores costumam coletar menos material de valor, uma vez que o próprio consumidor faz contato direto com os atravessadores. Já em épocas que o preço do material abaixa, os consumidores optam por entregar seus resíduos aos catadores.

Quando possível, os gestores de ecopontos buscam poupar recursos para investir em planos futuros que melhorem sua atuação e permitem coletar maiores quantidades de matérias. Ademais, todos os entrevistados demonstram consciência do impacto socioeconômico gerado, assim como orgulho da prestação do serviço que sustenta suas famílias e daqueles que atuam no mesmo ramo da reciclagem.

R. gest. sust. ambient., Florianópolis, v. 10, n. 2, p. 125-149, jun. 2021. 
Entretanto, observou-se que existem impactos sociais não perceptíveis por estes indivíduos no que tange a diminuição de aterros sanitários e suas problemáticas (Siqueira \& Moraes, 2009; CEMPRE, 2014). Ademais, por meio da coletividade do trabalho, existe uma rede de apoio entre catadores, ecopontos, cooperativas e algumas vezes, gestores de ferro velhos. Essa rede de apoio funciona por iniciativa dos indivíduos que visa auxiliar seus parceiros de trabalho, configurando ações realizadas de forma altruísta que permitem um bem comum. $A$ exemplo pode-se citar o caso de um dos gestores o qual, quando disposto a coletar material, opta pela coleta em regiões afastadas do seu ecoponto, principalmente quando este possui um caminhão. Assim, este profissional dá preferência que a coleta local seja feita por carroceiros individuais.

Ainda segundo os entrevistados, há uma percepção positiva acerca dos mesmos por grande parte da sociedade. As observações sobre os impactos sociais para catadores condizem com os apontamentos realizados por Cruz e Quandt (2007) e Leite (2000). Entretanto, um fato importante é que aqueles que possuem um veículo para trabalhar sofrem menos preconceito em comparação àqueles que atuam com carrinhos.

Uma das características reconhecidas por todos os entrevistados de ecopontos é o conhecimento do impacto ambiental positivo gerado com a destinação correta dos resíduos sólidos, impedindo estes de contaminarem o meio ambiente, cujos resultados do impacto ambiental são informados mensalmente pela prefeitura nas reuniões. Os gestores e catadores agem, portanto, como conscientizadores sobre os temas de reciclagem e resíduos sólidos para os frequentadores dos ecopontos tirando dúvidas, realizando apontamentos e direcionando os materiais ao destino correto. Contudo, estes indivíduos não reconhecem os impactos decorrentes da utilização de materiais recicláveis pela indústria, que diminui a demanda de matéria prima bruta, pois por vezes, o reprocessamento demanda menor quantidade de recursos e emite menos poluentes (ANCAT, 2018, Siqueira \& Moraes, 2009, CEMPRE, 2014), como evidenciado por Leite (2000).

Por fim, a principal reclamação foi a respeito de furtos de materiais recicláveis ou situações de vandalismo que ocorrem no período noturno, acarretando em grandes perdas. Há, ainda, a problemática da falta de estrutura local, como áreas cobertas, fato prejudicial ao rendimento em dias de chuva ou de

R. gest. sust. ambient., Florianópolis, v. 10, n. 2, p. 125-149, jun. 2021. 
sol forte. Tais evidências também foram pautadas na pesquisa em Limeira de Alvarez (2014) e são citadas por Giannetti et al. (2013).

\subsection{ENTREVISTA COM ATRAVESSADORES}

Nesta seção, foram entrevistados atravessadores de portes e regiões diferentes. Segundo o relato dos entrevistados, o ramo de reciclagem é altamente competitivo e flutuante, uma vez que os preços dos materiais variam mensalmente e exigem, principalmente dos entrantes no ramo, planejamento para evitar falência. Em períodos de alta de preços, é comum haver maior número de novos ingressantes ou atuantes, bem como o aumento do volume de material comercializado, gerando maior competitividade no setor. Tal competitividade de mercado gera a oscilação no contato com fornecedores, os quais buscam comercializar com base nos melhores valores. Importante entender que a alta do preço não reflete necessariamente em aumento de lucro, pois com a alta da concorrência afeta a margem de lucro padrão.

O cálculo de preço médio para a venda do material é realizado pelas indústrias com base nas características dos materiais, no potencial a longo prazo do atravessador e na fidelidade de comercialização. Já para o atravessador, a estratégia de precificação pode ser feita a partir da estipulação de um preço básico que proporcione a maior margem possível de lucro, cobrindo seus custos e despesas fixas. Tal precificação também é negociada entre a concorrência para que não haja prejuízo coletivo.

A partir do preço básico, há uma margem limite de variação conforme particularidades do fornecedor, tais como quantidade de material, frequência de entrega, qualidade do material, presença de impurezas e processamento do material. Por vezes, é comum o atravessador tirar o lucro mínimo em alguns produtos de um fornecedor para garantir a entrega de outros materiais, promovendo uma determinada fidelização.

Segundo os entrevistados, a escolha da especialização de material varia da estratégia de rentabilidade e limitações operacionais do empreendedor, tais como tamanho da área de operação, capital de giro e capital de investimento empregado,

R. gest. sust. ambient., Florianópolis, v. 10, n. 2, p. 125-149, jun. 2021. 
sendo que para diferentes materiais, são necessários diferentes aparatos e técnicas de trabalho (Leite, 2000). Como exemplo, para aparas de papel é necessário que haja um ambiente coberto para evitar o efeito das chuvas no material, enquanto o aço não apresenta a mesma problemática, a não ser pela exposição do mesmo em ambientes que possam causar problemas sanitários, como a dengue por exemplo. Já com os plásticos é necessário um grande espaço para acomodação e, também é aconselhável o uso de esteiras rolantes para que a triagem dos diferentes tipos de plásticos seja realizada. Com metais nobres e com o alumínio, é recomendada uma área fechada com segurança, por estes serem materiais de alto valor agregado e dificilmente recuperáveis pós furto.

Para pequenos e médios atravessadores que atuam no segmento de metais, um dos principais pontos positivos em relação ao desenvolvimento sustentável, é a possibilidade de pessoas físicas, sem qualquer relação com o mercado de reciclagem, inspecione montantes de materiais em busca daqueles em bom estado de conservação para a integrados aos subsistemas de reuso ou remanufatura, isto é, utilizando parcialmente ou completamente de produtos conservados para reposição de peças antigas ou para reparos, possibilitando ao produto uma reutilização aumentando sua vida útil. Este fenômeno se mantém condizente com as afirmações realizadas por Leite (2009). Alguns sucateiros, inclusive, se especializam na prática de aquisição ou separação desses materiais como forma de obtenção de uma renda extra, pois embora a ocorrência dessa espécie de produto seja menos frequente, a rentabilidade destes é maior em comparação aos resíduos destinados à reciclagem. Tal modalidade é popularmente conhecida como "sucata de escolha".

Por disporem de maiores investimentos e equipamentos do que catadores de reciclagem, os atravessadores utilizam tal vantagem para comprarem materiais recicláveis em um raio de maior atuação incluindo fábricas, médios e grandes comércios, empresas de construção civil e inclusive de outros sucateiros. Os atravessadores utilizam também da aquisição de seus equipamentos para seguir normas de qualidade impostas pela indústria, a fim de adquirir melhores preços e vantagem competitiva. Em outras palavras, o aumento de preços é repassado para o restante da cadeia como forma de incentivo para a compra em maiores volumes, como também uma forma de fidelizar os fornecedores.

R. gest. sust. ambient., Florianópolis, v. 10, n. 2, p. 125-149, jun. 2021. 
Os atravessadores relatam também manter uma boa relação com os catadores, visto que a atividade de coleta de materiais é o pilar básico da cadeia de reciclagem. Para manter um relacionamento mais estreito, os atravessadores promovem café da manhã para os catadores a fim de manter um ambiente de trabalho mais instigante.

Ainda sobre um maior estreitamento da relação entre atravessador e catador, os atravessadores apontaram ter consciência a respeito da importância do trabalho de coleta de materiais como base de sustentação de muitas famílias. Assim, uma relação que permite maior negociação, favorece investimentos na área que impactam positivamente na manutenção dos preços repassados.

A atuação dos atravessadores ultrapassa o ramo da reciclagem, a partir do oferecimento de serviços de manutenção e venda peças para dos próprios equipamentos utilizados na operação, gerando interações e movimentações financeiras em outros setores.

A conscientização pessoal a respeito do impacto positivo ambiental da reciclagem se demonstra diferente em certos casos. Para os atravessadores que não utilizam de meios de promoção com a temática "reciclagem", o conhecimento sobre os impactos ambientais se mostra limitado à destinação correta dos resíduos sólidos e ao impedimento dos impactos ao meio ambiente. Por sua vez, médios e grandes atravessadores utilizam da reciclagem como meios de promoção ou institucionalização, como apontado por Leite (2000, 2009), para gerar conteúdo informativo a respeito desta atividade, de forma a promover conscientização sobre os danos oferecidos pelo descarte incorreto de resíduos sólidos no meio ambiente. Assim, tal conteúdo serve como um manual instrutivo a respeito do tema, auxiliando consumidores comuns e possivelmente novos ingressantes no ramo sobre impactos também econômicos promovidos pela economia de recursos empregados no reprocessamento do material (ANCAT, 2018, Siqueira \& Moraes, 2009, CEMPRE, 2014).

De maneira geral e devido as indústrias não conseguirem sanar a necessidade de recuperar seus produtos através da lógica reversa - dada a fragmentação dos produtos, alto custo envolvido, contaminação com outros materiais, dentre outros fatores - surge nessa lacuna o desenvolvimento do trabalho de catadores e atravessadores para recuperar os resíduos, realizando processos de

R. gest. sust. ambient., Florianópolis, v. 10, n. 2, p. 125-149, jun. 2021. 
coleta, triagem, processamento e destinação ao restante da cadeia logística do material, que são comumente destinados às indústrias que realizam o reprocessamento do material (D'Adamo, 2019).

Tal lacuna tem se tornado um ambiente próspero a exploração comercial beneficiando em larga escala a sociedade em geral, uma vez que evitar a destinação incorreta dos resíduos, os quais podem acarretar na contaminação de outros ambientes, bem como possibilitando a recuperação econômica de parte do valor e reintegrando o material aos processos de consumo da sociedade.

Ademais, embora os catadores sejam considerados o elo mais fraco da cadeia logística e sofrerem os efeitos do preconceito social, eles compõem a base da logística reversa e da reutilização de materiais. Neste sentido, o cenário de valorização do profissional catador vem mudando com o estabelecimento de leis estaduais e projetos municipais que auxiliam os trabalhadores. Os projetos de ecopontos surgem nesse ambiente favorecendo o trabalho da reciclagem com 0 fornecimento de estruturas de trabalho e contato com atravessadores, evidências apontadas por Giannetti et al. (2013).

Com isso, a partir das presentes descobertas espera-se a disseminação desse conteúdo aos órgão governamentais e empresariais a respeito da importância dos agentes do processo logístico como forma de aprofundar os estudos sobre o tema e, consequentemente, valorizando a atuação desses profissionais informatizando a população sobre os benefícios dessa profissão, bem como realizando apontamentos de melhorias para a área, uma vez há espaços para maiores contribuições que necessitam vir atreladas a melhorias das condições de trabalho para os catadores individuais e coletivos (Cornieri \& Fracalanza, 2010). Ademais, a formalização do trabalho de reciclagem e 0 treinamento desses profissionais para manejo correto dos resíduos, pode colaborar para que se alcance a sustentabilidade local (Pegorin \& Araújo, 2018) além de fortalecer o trabalho coletivo para que as barreiras da logística reversa seja superada e implementada de forma a contemplar os catadores e atravessadores (Giannetti et al., 2013).

R. gest. sust. ambient., Florianópolis, v. 10, n. 2, p. 125-149, jun. 2021. 


\section{CONSIDERAÇÕES FINAIS}

A problemática do descarte incorreto de resíduos sólidos se mostra como um dos grandes desafios a serem superados para atingir o desenvolvimento sustentável. Os resíduos sólidos são materiais descartados após não apresentarem mais utilidade para o consumidor primário, todavia o material ainda pode apresentar utilidades para os subsistemas de reuso e remanufatura, além da possibilidade de reciclagem, reintegrando a cadeia de consumo como novos produtos.

Todavia, o trabalho de reciclagem não é de conhecimento geral da população e, por muitas vezes, os agentes da base da cadeia produtiva, os catadores, são desvalorizados socialmente, por mais que estes catadores trabalham em situações muitas vezes insalubres para garantir que os resíduos não sejam descartados de forma incorreta no espaço urbano, no meio ambiente ou destinado juntamente com material orgânico.

Neste contexto, a presente pesquisa visou identificar as contribuições sociais e ambientais dos recicladores e dos ferros velhos para os canais reversos de resíduos sólidos, abordando os três subsistemas reversos: reuso, remanufatura e reciclagem sob a ótica dos catadores e atravessadores.

A partir de estudos de caso, pode-se identificar que os atravessadores, por sua vez, realizam a intermediação entre a indústria de reciclagem e os demais agentes. Dada a estrutura comercial e equipamentos que os atravessadores possuem, eles conseguem comercializar os materiais em grandes quantidades e, inclusive, seguem protocolos de qualidade que a indústria requisita. Também foi possível observar parte da atuação de catadores individuais, coletivos e atravessadores no que diz respeito às estratégias empregadas para potencializar o funcionamento dos locais de recebimento e armazenamento dos materiais recicláveis. Também se percebeu o sentimento de orgulho dos que pertencem ao segmento de negócio pela promoção dos benefícios que a reciclagem proporciona à sociedade e ao meio ambiente.

No caso dos catadores individuais, sem vínculos com projetos públicos ou entidades coletivas, não foi detectado o conhecimento dos mesmos com relação aos benefícios sociais e ambientais do trabalho. Já com aqueles que atuam em coletivo ou vinculados a projetos sociais ou públicos, notou-se maior conhecimento acerca

R. gest. sust. ambient., Florianópolis, v. 10, n. 2, p. 125-149, jun. 2021. 
dos impactos sociais e ambientais gerados pelas atividades no que tange à uma maneira de renda e a possibilidade de destinação correta de resíduos sólidos. Assim, conforme pontua Cruz e Quandt (2007), o trabalho coletivo colabora com o desenvolvimento pessoal, cultural, político e social do indivíduo.

Quanto aos atravessadores, estes demonstram maior conhecimento acerca dos impactos sociais de seu trabalho, para além dos ganhos próprios, tendo ciência que suas ações e investimentos geram impactos em outros envolvidos da cadeia logística. Ademais, a percepção ambiental pelos mesmos se mostra como objetivo secundário, uma vez que os trabalhos de conscientização externa e geração de conteúdo ambiental é realizado por médios e grandes atravessadores que utilizam desse trabalho como forma de superar a concorrência. No ambiente socioeconômico, os atravessadores são responsáveis por movimentar grandes quantidades de recursos financeiros aos consumidores iniciais, industrias e aos catadores, mantendo um relacionamento positivo a fim de garantir fidelidade.

De maneira geral, a questão principal foi obtida de forma satisfatória. Podese afirmar que as contribuições sociais e ambientais dos recicladores e dos ferros velhos para os canais reversos de resíduos sólidos se dá por: a) os catadores que possuem contato com projetos públicos municipais demonstram maior entendimento a respeito do impacto social e ambiental; enquanto b) os atravessadores possuem conhecimento do impacto social por vivenciarem as mudanças econômicas pessoais e de outros agente; e c) todavia para uma parcela de pequenos e médios atravessadores o impacto ambiental é conhecido, mas não é gerado um processo de conscientização dos colaboradores ou da sociedade, sendo esse, um foco de médios e grandes atravessadores que utilizam tal estratégia como forma de sobressaírem diante à concorrência.

Dentre as limitações do estudo, pode-se destacar que, embora foi possível obter resultados satisfatórios a respeito da questão de pesquisa proposta, podendo ser observado as estratégias empregadas no trabalho realizado, bem como as interações entre catadores, atravessadores e a sociedade, uma das dificuldades foi em relação a obtenção valores e quantidade de quilos comercializados pelos atravessadores, pois são informações privadas cujos entrevistados relutaram em informar. Outra dificuldade diz respeito aos lucros dos atravessadores, os quais

R. gest. sust. ambient., Florianópolis, v. 10, n. 2, p. 125-149, jun. 2021. 
alegaram que devido à sazonalidade do valor pago aos materiais, eles preferiram não informar.

Como sugestão para pesquisas futuras, se mostra necessário aprofundamentos pela ótica administrativa na questão operacional dos atravessadores e coletores que atuam em coletivo, buscando agregar a ótica do comercio de recicláveis que possui peculiaridades, como o comportamento inverso da cadeia logística de funcionamento para profissionais de diversas áreas, possibilitando maior reconhecimento da atuação dos agentes de recicláveis.

\section{REFERÊNCIAS}

Associação Brasileira de Empresas de Limpeza Pública e Resíduos Especiais (ABRELPE) (2017). Panorama dos resíduos sólidos no Brasil (15ª ed.). São Paulo.

Alvarez, A. C. S. (2014). A gestão dos ecopontos: um estudo de caso do município de Limeira (Monografia). Faculdade de Ciências Aplicadas, Universidade Estadual de Campinas, São Paulo.

Aguiar, A. (1999). As parcerias em programas de coleta seletiva de resíduos sólidos domésticos (Dissertação de mestrado). Faculdade de Saúde Pública, Universidade de São Paulo, São Paulo.

Asim, M., Batool, S. A., \& Chaudhry, M. N. (2012). Scavengers and their role in the recycling of waste in Southwestern Lahore. Resources, Conservation And Recycling, 58, 152-162. http://dx.doi.org/10.1016/j.resconrec.2011.10.013

Associação Nacional dos Catadores e Catadoras de Materiais Recicláveis (ANCAT) (2018). Anuário da Reciclagem 2017-2018. São Paulo.

Benbasat, I., Goldstein, D.K., \& Mead, M. (1987). The case research strategy in studies of information systems. MIS Q., 11. 369-386.

Carmo, M. S, Oliveira, J. A. P., \& Arruda, R. G. L. (2006). O trabalho com residuos pelos classificadores: o papel da semântica do lixo no reconhecimento social e identidade profissional. In Anais do XXX Encontro Anual da ANPAD. Salvador: ANPAD.

Chagas, H. P. \& Neto, J. A. (2012). O cenário brasileiro da indústria de reciclagem. In XXXII Encontro Nacional de Engenharia de Produção. São Paulo: ENEGEP.

Compromisso Empresarial para Reciclagem (CEMPRE) (2014). Guia da coleta seletiva de lixo (2ª ed.). São Paulo.

Cornieri, M. \& Fracalanza, A. P. (2010). Desafios do lixo em nossa sociedade. Revista Brasileira de Ciências Ambientais, 16, 57-64.

R. gest. sust. ambient., Florianópolis, v. 10, n. 2, p. 125-149, jun. 2021. 
Cruz, J. A. W. \& Quandt, C. O. (2007). Redes, cooperação e desenvolvimento: estudo de caso em uma rede de associações de coletores de materiais recicláveis. In Anais do XXXI Encontro Anual da ANPAD. Rio de Janeiro: ANPAD.

D’Adamo, I., Ferella, F., Gastaldi, M., Maggiore, F., Rosa, P., \& Terzi, S. (2019). Towards sustainable recycling processes: wasted printed circuit boards as a source of economic opportunities. Resources, Conservation And Recycling, 149(9), 455467. http://dx.doi.org/10.1016/j.resconrec.2019.06.012.

Denzin, N. (1978). The research act: a theoretical introduction to sociological methods (2aㅡ. ed.). Nova York: Mc Graw-Hill.

Figueiredo, F. F. (2012). O desenvolvimento da indústria da reciclagem dos materiais no Brasil: motivação econômica ou benefício ambiental conseguido com a atividade? Revista Electrónica de Geografía y Ciencias Sociales, 16(387).

Giannetti, B. F., Bonilla, S. H., \& Almeida, C. M. V. B. (2013). An emergy-based evaluation of a reverse logistics network for steel recycling. Journal Of Cleaner Production, 46, 48-57. http://dx.doi.org/10.1016/i.jclepro.2012.05.024.

Gonçalves-Dias, S. L. F., \& Teodósio, A. S. S. (2006). Estrutura da cadeia reversa: "caminhos" e "descaminhos" da embalagem PET. Produção, 16(3), 429-441.

Klein, B. F., Gonçalves-Dias, S. L. F., \& Jayo, M. (2018). Gestão de resíduos sólidos urbanos nos municípios da Bacia Hidrográfica do Alto Tietê: uma análise sobre o uso de TIC no acesso à informação governamental. Revista Brasileira de Gestão Urbana, 10(1), 140-153. https://doi.org/10.1590/2175-3369.010.001.AO103.

Leite, P. R. (2000). Canais de Distribuição Reversos: fatores de Influência sobre as Quantidades Recicladas de Materiais. In Anais do III Simpósio de Administração da Produção, Logística e Operações Internacionais da Fundação Getúlio Vargas. São Paulo: SIMPOI.

Leite, P. R. (2009). Logística reversa: meio ambiente e competitividade (2ª ed.). São Paulo: Pearson Prentice Hall.

Medeiros, L. F. R., \& Macêdo, K. B. (2006). Catador de material reciclável: uma profissão para além da sobrevivência? Psicologia \& Sociedade, 18(2), 62-71.

Medina, M. (1997). Informal recycling and collection of solid wastes in developing countries: issues and oportunities. Working paper. United Nations University.

Medina, M. (2000) Scavenger cooperatives in Asia and Latin America. Resources, Conservation and Recycling, 31(1), 51-69.

Organização das Nações Unidas (ONU) (2018). Humanidade produz mais de 2 bilhões de toneladas de lixo por ano, diz ONU em dia mundial.

Pacheco, J. (2019). Análise da Cadeia da Reciclagem (Monografia). Universidade Regional do Noroeste do Estado do Rio Grande do Sul, Rio Grande do Sul.

R. gest. sust. ambient., Florianópolis, v. 10, n. 2, p. 125-149, jun. 2021. 
Paiva, V. (2004). Las cooperativas de recuperadores y la gestión de residuos sólidos urbanos en el área metropolitana de Buenos Aires. Theomai Journal, 99.

Pegorin, M. C., \& Araújo, T. R. P. P. (2018). Saneamento e coleta de resíduos sólidos: desafios para a sustentabilidade em municípios brasileiros. In Anais do XX Encontro Internacional sobre Gestão Empresarial e Meio Ambiente. São Paulo. São Paulo: ENGEMA.

Perlin, A. P., Alvares, M. V., Kneipp, J. M., Vestena, D., \& Rossato, G. (2020). Gestão de resíduos sólidos em uma organização militar do Rio Grande do Sul. Revista Gestão \& Sustentabilidade Ambiental, 9(3), 500-571, 2020. http://dx.doi.org/10.19177/rgsa.v9e32020500-520.

Rodriguez, C. (2007). À procura de alternativas econômicas em tempos de globalização: o caso das cooperativas de recicladores de lixo na Colômbia. In Sachs, I. Rumo à ecossocioeconomia: teoria e prática do desenvolvimento. São Paulo: Cortez.

Souza, M. T. S., Paula, M. B., \& Souza-Pinto, H. S. (2012). O papel das cooperativas de reciclagem nos canais reversos pós-consumo. Revista de Administração de Empresas, 52(2), 246-262.

Siqueira, M. M. S, \& Moraes, M. S. (2009). Saúde coletiva, resíduos sólidos urbanos e os catadores de lixo. Ciência \& Saúde Coletiva, 14(6), 2115-2122.

Women in Informal Employment Globalizing and Organizing (WIEGO) (2008). Enfocándonos en las trabajadoras informales: recicladoras de basura.

R. gest. sust. ambient., Florianópolis, v. 10, n. 2, p. 125-149, jun. 2021. 